\title{
CORRECTION
}

\section{Correction to: RF-ablation pattern shaping employing switching channels of dual bipolar needle electrodes: ex vivo results} \author{
Michael Friebe ${ }^{1}$ \\ Published online: 3 July 2018 \\ (c) CARS 2018

\section{Correction to: \\ International Journal of Computer Assisted Radiology \\ and Surgery (2018) 13:905-916} \\ https://doi.org/10.1007/s11548-018-1769-8 \\ The original version of this article was published without \\ funding note. The funding note is given below. \\ The research reported in this paper was supported by the \\ National Institute of Biomedical Imaging and Bioengineer- \\ ing of the National Institutes of Health under Award Number \\ R01EB021396 and National Science Foundation under Pro- \\ posal Number 1653322.
}

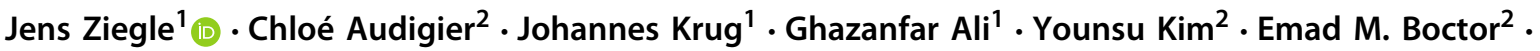

The original article can be found online at https://doi.org/10.1007/s11 548-018-1769-8.

$凶$ Jens Ziegle

jens.ziegle@ovgu.de

Chloé Audigier

caudigi1@jhmi.edu

1 Department of Medical Engineering, Otto-von-Guericke University, Magdeburg, Saxony-Anhalt, Germany

2 Department of Computer Science, Johns Hopkins University, Baltimore, MD, USA 